\title{
Cardiovascular co-morbidity in patients with rheumatic diseases
}

\author{
Johan Frostegård*
}

\begin{abstract}
During recent years atherosclerosis, the major cause of cardiovascular disease (CVD), has been recognised as a chronic inflammatory condition in which rupture of atherosclerotic lesions appears to play a major role. The risk of CVD is raised in many rheumatic diseases. This risk is high in systemic lupus erythematosus - as much as a 50-times increase among middle-aged women has been reported. Studies on CVD and atherosclerosis in rheumatic disease could thus provide interesting information about CVD and atherosclerosis in addition to being an important clinical problem. A combination of traditional and nontraditional risk factors accounts for the increased risk of CVD and atherosclerosis in rheumatic disease. One interesting possibility is that atherosclerotic lesions in rheumatic disease are more prone to rupture than normal atherosclerotic lesions. It is also likely that increased risk of thrombosis may play an important role, not least in systemic lupus erythematosus. Further, it is not clear whether an increased risk of CVD is a general feature of rheumatic disease, or whether this only occurs among subgroups of patients. It should be emphasised that there is an apparent lack of treatment studies where CVD in rheumatic disease is the end point. Control of disease activity and of traditional risk factors, however, appears to be well founded in relation to CVD in rheumatic disease. Further studies are needed to determine the exact role of lipid-lowering drugs as statins. Hopefully novel therapies can be developed that target the causes of the inflammation in atherosclerotic lesions both in rheumatic patients and in the general population.
\end{abstract}

*Correspondence: johan.frostegard@ki.se

Institute of Environmental Medicine, Unit of Immunology and Chronic Disease, Karolinska Institutet, 17177 Stockholm, Sweden

\section{Introduction}

The history of ideas and hypotheses about atherosclerosis is interesting. The inflammatory nature of atherosclerosis and the involvement of immune competent cells was described by the Austrian pathologist Karl Rokitansky in the 1840 s and by the pathologist and social medicine pioneer Rudolf Virchow somewhat later in the 1850s [1]. As discussed in a previous editorial [2], these two important persons in the history of medicine had an interesting argument: Rokitansky believed that the inflammation in atherosclerosis was secondary to other disease processes, but Virchow instead suggested that atherosclerosis is a primary inflammatory condition. The relevance of this discussion to cardiovascular disease (CVD) and atherosclerosis in rheumatic disease is obvious, and in fact both arguments were most probably right. Virchow clearly had a point verified in an interesting paper based on studies of Rokitansky's own arterial pathological specimens. Here, activated $\mathrm{T}$ cells and other inflammatory and immune competent cells are present already at a very early stage of disease, which in principle adds support to Virchow's opinions [1]. A recent meta-analysis indicates that rheumatic diseases raise the risk of premature atherosclerosis, implying that inflammatory conditions such as in rheumatic diseases could have secondary atherosclerosis as a side effect [3]. Both Rokitansky and Virchow were right, in a nonmutually exclusive way.

It was not until the early 1980s that the inflammation/ immune hypothesis in atherosclerosis surfaced [4,5], although Russell Ross came close 1977 with his response to injury hypothesis [6]. Before that, the field was dominated by the lipid hypothesis - attention was paid especially to cholesterol in the blood as a risk factor. Initially, it appeared that these two ideas about the nature of the disease contradicted each other, but now there appears to be consensus that both are relevant and nonmutually exclusive, and each probably plays a different role depending on patient groups.

Interestingly, statins can illustrate this dual nature of atherosclerosis and CVD. Statins are, from a commercial point of view, among the most successful medicines in history. In fact, they may be beneficial not only due to the 
mechanism for which they were developed but, in addition, for pleiotropic effects including anti-inflammatory effects (caused by influencing prenylation among other processes), antioxidant effects, decreasing lowdensity lipoprotein (LDL) oxidation, and even immune modulatory effects, decreasing MHC class 2 interaction with antigen [7]. The Jupiter study recently demonstrated that statin treatment may be beneficial for individuals with raised high-sensitivity C-reactive protein but normal LDL [8].

\section{The nature of atherosclerosis and cardiovascular disease}

Atherosclerosis is an inflammatory process in large and middle-sized arteries, where activated monocytes/ macrophages and $\mathrm{T}$ cells are present in the intima $[9,10]$. Proinflammatory cytokines are produced by immune competent cells in the lesions [9-11]. In addition to chronic inflammation, atherosclerosis also shares characteristics with autoimmune diseases - as indicated by studies where adoptive transfer of $\beta_{2}$-glycoprotein Ireactive lymphocytes enhances atherosclerosis in animal models [12].

Of note, atherosclerosis per se is widespread in the population. Atherosclerosis has been detected in Egyptian mummies, and also in young adult humans. Further, and surprisingly, even foetal atherosclerosis in the form of early changes (fatty streaks) has been determined [13]. One could therefore debate whether atherosclerosis indeed is a disease and not a normal aspect of human aging.

Even though narrow lumens caused by noncomplicated atherosclerosis may be a problem in some cases, however, it is the development of atherosclerotic plaques into more complicated lesions - where fissures and even microthrombae and eventually plaque rupture occur - that leads to CVD, including stroke and acute coronary syndrome, heart failure (as a later consequence of acute coronary syndrome), and claudication. One major issue is therefore the cause of plaque rupture. Inflammation plays a major role, although the exact mechanisms are not known. Activation of proinflammatory cytokines and chemokines are prominent features of plaque rupture. One interesting possibility is therefore that the proinflammatory state in rheumatic disease per se may promote atherosclerotic plaque rupture.

An interesting development is the possibility of immunisation, active or passive (administering antibodies), against atherosclerosis and/or CVD. Not unexpectedly, LDL is a target - examples of antigens as culprits include apolipoprotein B peptides [14] (apolipoprotein B being the major carrier protein in LDL) or antigens in the phospholipid moiety such as phorphorylcholine (PC). Natural IgM antibodies against PC (anti-PC) are negatively associated with human atherosclerosis [15] and low levels of anti-PC predict increased risk of CVD independent of other risk factors [16-18].

In the above-mentioned meta-analysis where rheumatic disease and atherosclerosis were determined, it was demonstrated that there is indeed a premature atherosclerosis in general. In this study, cases and matched controls where identified through systematic analysis on PubMed and 68 comparisons from 60 different studies were made. Taken together, of patients included in this meta-analysis, 37\% had rheumatoid arthritis (RA), 35\% had systemic lupus erythematosus (SLE), 9\% had systemic sclerosis, and 19\% had other rheumatic diseases [3].

In both SLE and RA, an association between CVD and extent of atherosclerosis has been established [19,20]. This association points to atherosclerosis as a major underlying factor in co-morbidity between rheumatic diseases (at least SLE and RA) and CVD.

\section{Systemic lupus erythematosus}

Since the inflammatory nature of atherosclerosis was not in focus until the 1980s, it is not surprising that little attention was paid to associations between CVD and rheumatic disease. In an early report from 1976, however, a bimodal pattern of SLE was reported [21], According to this paper, in addition to early direct effects of SLE on various organ systems, a later complication was CVD [21].

Before immunosuppressive treatment was implemented, more acute SLE manifestations, such as nephritis, were often fatal. Early autopsy and angiographic studies also demonstrated that the prevalence of atherosclerotic lesions is high in SLE $[22,23]$.

The strong association between SLE and CVD has been firmly established in many reports. This risk can be very high in some patient groups: according to one study, women aged 44 to 50 had a 50-times increased risk of myocardial infarction [24]; and an increased CVD risk in SLE is well documented [25]. Indeed, T-helper type 2 cytokines have been associated with SLE and at the same time inhibit atherosclerosis in experimental animals [25]. Even though it is clear that the risk of CVD is raised in SLE, this possibly only applies to a subgroup of SLE patients. Information and advice for rheumatic patients in relation to CVD risk should take this possibility into account. Even though CVD is associated with atherosclerosis in SLE [20], thrombosis per se possibly adds to the risk [20].

A combination of traditional and nontraditional risk factors typically accounts for, statistically, the increased risk of CVD in SLE, although there are variations in studies - for example, in relation to the role of smoking. Dyslipidaemia (typically the lupus pattern with high triglycerides), hypertension and renal disease are in most studies significantly associated with CVD risk. 
Nontraditional factors such as inflammation and antiphospholipid antibodies (aPL) are also of importance in SLE, aPL more than in other rheumatic diseases. LDL is generally recognised as a risk factor in the general population, and LDL oxidation is believed to be of importance due to its proinflammatory, even toxic, effects and the uptake of oxidised LDL into the vascular wall, from which it is then not removed. It is therefore of interest that oxidised LDL in the circulation is raised in SLE $[20,25]$.

A possibility deserving further study is that atherosclerotic plaques in SLE are more prone to rupture. We recently determined by carotid ultrasound that vulnerable atherosclerotic plaques are more prevalent in SLE, lending support to this notion [26].

Emerging risk factors that also implicate novel mechanisms may play a role in SLE-related CVD. Two examples of this are, firstly, anti-PC and, secondly, the binding of annexin A5 and interaction with endothelial cells, aPL and inflammation.

Firstly, we reported recently that low levels of anti-PC independently predict CVD in general and that there is a negative association between anti-PC levels and development of human atherosclerosis, where high levels confer decreased atherosclerosis development after 5 years [27]. Further, low levels of anti-PC were associated with SLE in a nested case-control SLE study [28] - and in a new SLE case-control study we confirmed and extended this association, low levels of anti-PC being associated with prevalence of atherosclerotic plaques [29].

Mechanisms by which anti-PC could be beneficial include an anti-inflammatory effect whereby anti-PC inhibits endothelial activation caused by inflammatory phospholipids [28]. In principle, by this anti-inflammatory effect, low anti-PC could predispose to both atherosclerosis and rheumatic disease, suggesting one possible common underlying factor. Another mechanism could be decreased uptake of oxidised LDL in macrophages, which could lead to less atherosclerosis development [16].

Secondly, binding of annexin A5, which has antithrombotic properties, is decreased in individuals with SLE and CVD. This decreased binding is caused by aPL that outcompete annexin A5 binding, causing a prothrombotic state. We also demonstrated that annexin A5 is abundant in atherosclerotic plaques, at sites prone to plaque rupture, and suggested that this protein may stabilise plaques, protect endothelium and inhibit plaque rupture [30]. Further, pooled immunoglobulin (intravenous immunoglobulin; IVIG) can neutralise aPL and restore binding of annexin A5 [31].

\section{Rheumatoid arthritis}

The risk of CVD is also increased in RA, although not as strikingly as in SLE [32-35]. The risk varies in different studies, which could depend on the study populations chosen, age and other factors, including secular trends for RA per se. As in SLE, a combination of traditional and nontraditional risk factors, including inflammation and also extra-articular manifestations, appears to explain this increased risk [32-34,36-41].

For example, in young women a 3.6-times increased risk of death in coronary artery disease was reported, and in a population-based cohort of RA patients the incidence of myocardial infarction and coronary heart disease was 50\% higher in RA [32]. Similar results were obtained in other studies [42], and it has been suggested that RA is comparable with type 2 diabetes mellitus as an independent risk factor for CVD [43]. As in SLE, traditional CVD risk factors and inflammation-associated factors appear to be of major importance to explain the increased risk of CVD in RA [25]. The risk of CVD in RA may be decreasing [44].

While it thus appears that CVD is increased in RA and SLE (and other rheumatic diseases), the exact role of atherosclerosis/CVD and potential underlying mechanisms in RA has been less clear [25].

The role of rheumatoid factor in this context is not known, although interestingly rheumatoid factor is often present in smokers. Further, it is not clear how immune complexes in general, or even complement, affect RArelated cardiovascular co-morbidity. Perhaps complement could play a different role depending on the disease stage.

Another interesting development in RA is the role of citrullinated proteins and antibodies against these. Recent findings imply that such antibodies, increasingly recognised as important novel risk markers for RA, could also play an independent role in RA-related atherosclerosis and CVD, including ischaemic heart disease $[45,46]$.

In an interesting paper, functional polymorphisms relating to MHC-molecule expression were demonstrated to be associated with susceptibility to RA, multiple sclerosis and myocardial infarction [47], suggesting putative common mechanisms.

While many studies including the above-mentioned meta-analysis support an increased prevalence of atherosclerosis as determined by ultrasound of carotid arteries $[37,39,48]$, there are also studies where such an increase was not detected, either as the intima-media thickness or as prevalence of plaque [36]. In favour of arterial changes in RA (as in SLE) are studies in which endothelial dysfunction has been reported [49]. aPL and also antibodies against oxidised LDL are raised in RA but their clinical importance for CVD and atherosclerosis is not clear [50]. Lipid peroxidation may also play a role in RA, and oxidised LDL-containing foam cells have been described in RA synovia [51]. Further, oxidative stress is increased in RA and associated with atherosclerosis [52]. 
Another emerging factor in CVD is heat shock proteins, which are implicated in both RA and atherosclerosis although immune reactivity to heat shock proteins in RA appears to play a somewhat different role, being protective in many cases while it appears to be unfavourable in atherosclerosis and CVD [53].

Dyslipidaemia is often present in RA with low highdensity lipoprotein and high triglycerides in a similar way as in inflammatory and infectious diseases in general. An increased prevalence of potentially atherogenic, small, dense LDL particles were reported in RA, and LDL from RA patients also has an increased capacity to bind proteoglycans, which most probably is an important step in early atherogenesis [54].

As in SLE, the role played by treatment is of potential importance. Corticosteroids at moderate dose $(7.5 \mathrm{mg}$ prednisolone) did not affect atherosclerosis, but it is still possible they would affect atherosclerosis in higher doses - for example, the unfavourable metabolic effects may outweigh the anti-inflammatory properties [55]. The role of methotrexate has been debated, but recent investigations suggest such treatment with folate substitution could influence CVD risk factors in a beneficial way [56].

TNF inhibition could be expected to be antiatherogenic since TNF has proinflammatory and unfavourable metabolic effects [20]; in line with this, in a mouse model of atherosclerosis, TNF inhibition decreased atherosclerosis development [57]. Side effects such as heart failure are implicated [58]. In humans, however, TNF inhibition appears to have a favourable effect on CVD [59].

Even though statins may be implicated in RA (and potentially other rheumatic diseases) and indeed have an effect on RA per se [60], further studies are needed before general recommendations should be given.

\section{Other rheumatic diseases and atherosclerosis/ cardiovascular disease}

SLE and RA in relation to atherosclerosis and CVD have been studied more than other rheumatic diseases. In psoriatic arthritis, increased atherosclerosis has been reported [61,62] and an increased prevalence of CVD is well established with risk factors comparable with those in RA [63]. In ankylosing spondylitis, studies indicate that the risk of CVD is enhanced, but perhaps less so than in RA and SLE. Also in ankylosing spondylitis, dyslipidaemia and inflammation per se may play a role, and positive effects of TNF inhibitors are discussed [64-66].

In vasculitis, increased atherosclerosis has been noted both in Kawasaki's disease [67] and Takayasu's arteritis $[68,69]$. In Behçet's disease, where vasculitis commonly occurs, and in Wegener's granulomatosis, increased atherosclerosis as determined by carotid ultrasound has also been reported [70,71].

Gout has been associated with CVD and increased urate levels, but urate may also have antioxidant properties that may be beneficial under some circumstances [72].

\section{Summary and conclusions}

Both atherosclerosis and the risk of CVD are increased in rheumatic diseases, especially in SLE, and the risk appears to be strikingly high. The underlying mechanisms are probably related to atherothrombosis and increased prevalence of atherosclerotic plaques where traditional and nontraditional risk factors act in concert. When treating patients with rheumatic disease, it is important to pay attention to the increased risk of CVD. Traditional risk factors as dyslipidaemia, hypertension, diabetes and smoking should be closely monitored and disease symptoms including inflammation should be treated. Hopefully novel therapeutic modalities will be developed that target the causes of the inflammation present in atherosclerotic lesions.

This article is part of the series Comorbid conditions in subjects with rheumatic diseases, edited by Daniel Aletaha and Thomas Dörner.

Other articles in this series can be found at

http://arthritis-research.com/series/comorbid

\section{Abbreviations}

anti-PC, natural IgM antibodies against phorphorylcholine; $\mathrm{APL}$ antiphospholipid antibodies; CVD, cardiovascular disease; LDL, low-density lipoprotein; PC, phorphorylcholine; RA, rheumatoid arthritis; SLE, systemic lupus erythematosus; TNF, tumour necrosis factor.

\section{Competing interests}

The author declares that he has no competing interests.

Published: 30 June 2011

\section{References}

1. Mayerl C, Lukasser M, Sedivy R, Niederegger H, Seiler R, Wick G: Atherosclerosis research from past to present - on the track of two pathologists with opposing views, Carl von Rokitansky and Rudolf Virchow. Virchows Arch 2006, 449:96-103.

2. Frostegard J: Rheumatic diseases: insights into inflammation and atherosclerosis. Arterioscler Thromb Vasc Bio/ 2010, 30:892-893.

3. Tyrrell PN, Beyene J, Feldman BM, McCrindle BW, Silverman ED, Bradley TJ: Rheumatic disease and carotid intima-media thickness: a systematic review and meta-analysis. Arterioscler Thromb Vasc Bio/ 2010, 30:1014-1026.

4. Hansson GK, Jonasson L: The discovery of cellular immunity in the atherosclerotic plaque. Arterioscler Thromb Vasc Biol 2009, 29:1714-1717.

5. Jonasson L, Holm J, Skalli O, Bondjers G, Hansson GK: Regional accumulations of T cells, macrophages, and smooth muscle cells in the human atherosclerotic plaque. Arteriosclerosis 1986, 6:131-138.

6. Ross R, Glomset J, Harker L: Response to injury and atherogenesis. Am J Pathol 1977, 86:675-684.

7. Wang CY, Liu PY, Liao JK: Pleiotropic effects of statin therapy: molecular mechanisms and clinical results. Trends Mol Med 2008, 14:37-44.

8. Ridker PM, Danielson E, Fonseca FA, Genest J, Gotto AM, Jr, Kastelein JJ, Koenig W, Libby P, Lorenzatti AJ, MacFadyen JG, Nordestgaard BG, Shepherd J, Willerson JT, Glynn RJ: Rosuvastatin to prevent vascular events in men and women with elevated C-reactive protein. N Engl J Med 2008, 
359:2195-2207.

9. Ross R: Atherosclerosis - an inflammatory disease. N Engl J Med 1999, 340:115-126.

10. Hansson GK: Inflammation, atherosclerosis, and coronary artery disease. N Engl J Med 2005, 352:1685-1695.

11. Frostegard J, Ulfgren AK, Nyberg P, Hedin U, Swedenborg J, Andersson U, Hansson GK: Cytokine expression in advanced human atherosclerotic plaques: dominance of pro-inflammatory (Th1) and macrophagestimulating cytokines. Atherosclerosis 1999, 145:33-43.

12. George J, Harats D, Gilburd B, Afek A, Shaish A, Kopolovic J, Shoenfeld Y: Adoptive transfer of beta(2)-glycoprotein I-reactive lymphocytes enhances early atherosclerosis in LDL receptor-deficient mice. Circulation 2000, 102:1822-1827.

13. Napoli C, D'Armiento FP, Mancini FP, Postiglione A, Witztum JL, Palumbo G, Palinski W: Fatty streak formation occurs in human fetal aortas and is greatly enhanced by maternal hypercholesterolemia. Intimal accumulation of low density lipoprotein and its oxidation precede monocyte recruitment into early atherosclerotic lesions. J Clin Invest 1997 100:2680-2690

14. Nilsson J, Hansson GK, Shah PK: Immunomodulation of atherosclerosis: implications for vaccine development. Arterioscler Thromb Vasc Biol 2005, 25:18-28

15. Su J, Georgiades A, Wu R, Thulin T, de Faire U, Frostegard J: Antibodies of IgM subclass to phosphorylcholine and oxidized LDL are protective factors for atherosclerosis in patients with hypertension. Atherosclerosis 2006, 188:160-166.

16. de Faire U, Su J, Hua X, Frostegard A, Halldin M, Hellenius ML, Wikstrom M, Dahlbom I, Gronlund H, Frostegard J: Low levels of IgM antibodies to phosphorylcholine predict cardiovascular disease in 60-year old men: effects on uptake of oxidized LDL in macrophages as a potential mechanism. J Autoimmun 2010, 34:73-79.

17. Fiskesund R, Stegmayr B, Hallmans G, Vikstrom M, Weinehall L, de Faire U, Frostegard J: Low levels of antibodies against phosphorylcholine predict development of stroke in a population-based study from northern Sweden. Stroke 2010, 41:607-612.

18. Sjoberg BG, Su J, Dahlbom I, Gronlund H, Wikstrom M, Hedblad B, Berglund G, de Faire U, Frostegard J: Low levels of IgM antibodies against phosphorylcholine - a potential risk marker for ischemic stroke in men Atherosclerosis 2009, 203:528-532

19. Evans MR, Escalante A, Battafarano DF, Freeman GL, O'Leary DH, Del Rincon l: Carotid atherosclerosis predicts incident acute coronary syndromes in rheumatoid arthritis. Arthritis Rheum 2011, 63:1211-1220.

20. Svenungsson E, Jensen-Urstad K, Heimburger M, Silveira A, Hamsten A, de Faire U, Witztum JL, Frostegard J: Risk factors for cardiovascular disease in systemic lupus erythematosus. Circulation 2001, 104:1887-1893.

21. Urowitz MB, Bookman AA, Koehler BE, Gordon DA, Smythe HA, Ogryzlo MA: The bimodal mortality pattern of systemic lupus erythematosus. Am J Med 1976, 60:221-225

22. Bulkeley $B H$, Roberts WC: The heart in systemic lupus erythematosus and the changes induced in it by corticosteroid therapy. Am J Med 1975, 58:243-264

23. Heibel RH, O'Toole JD, Curtiss El, Medsger TA, Jr, Reddy SP, Shaver JA: Coronary arteritis in systemic lupus erythematosus. Chest 1976, 69:700-703.

24. Manzi S, Meilahn EN, Rairie JE, Conte CG, Medsger TA, Jr, Jansen-McWilliams L, D'Agostino RB, Kuller LH: Age-specific incidence rates of myocardial infarction and angina in women with systemic lupus erythematosus: comparison with the Framingham Study. Am J Epidemiol 1997, 145:408-415.

25. Frostegard $\mathrm{J}$ : Atherosclerosis in patients with autoimmune disorders. Arterioscler Thromb Vasc Biol 2005, 25:1776-1785.

26. Anania C, Gustafsson T, Hua X, Su J, Vikstrom M, de Faire U, Heimburger M, Jogestrand T, Frostegard J: Increased prevalence of vulnerable atherosclerotic plaques and low levels of natural lgM antibodies against phosphorylcholine in patients with systemic lupus erythematosus. Arthritis Res Ther 2010, 12:R214.

27. Frostegard J: Low level natural antibodies against phosphorylcholine: a novel risk marker and potential mechanism in atherosclerosis and cardiovascular disease. Clin Immunol 2010, 134:47-54

28. Su J, Hua X, Concha H, Svenungsson E, Cederholm A, Frostegard J: Natural antibodies against phosphorylcholine as potential protective factors in SLE. Rheumatology (Oxford) 2008, 47:1144-1150.

29. Anania C, Gustafsson T, Hua X, Su J, Vikstrom M, de Faire U, Heimburger M,
Jogestrand T, Frostegard J: Increased prevalence of vulnerable atherosclerotic plaques and low levels of natural lgM antibodies against phosphorylcholine in patients with systemic lupus erythematosus. Arthritis Res Ther 2010, 12:R214.

30. Cederholm A, Svenungsson E, Jensen-Urstad K, Trollmo C, Ulfgren AK, Swedenborg J, Fei GZ, Frostegard J: Decreased binding of annexin $v$ to endothelial cells: a potential mechanism in atherothrombosis of patients with systemic lupus erythematosus. Arterioscler Thromb Vasc Biol 2005, 25:198-203.

31. Frostegard A, Su J, von Landenberg P, Frostegard J: Effects of anti-cardiolipin antibodies and IVIg on annexin A5 binding to endothelial cells: implications for cardiovascular disease. Scand J Rheumato/ 2010, 39:77-83.

32. Wallberg-Jonsson S, Ohman ML, Dahlqvist SR: Cardiovascular morbidity and mortality in patients with seropositive rheumatoid arthritis in Northern Sweden. J Rheumatol 1997, 24:445-451.

33. Myllykangas-Luosujarvi $\mathrm{R}$, Aho $\mathrm{K}$, Kautiainen $\mathrm{H}$, Isomaki H: Cardiovascular mortality in women with rheumatoid arthritis. J Rheumatol 1995, 22:1065-1067.

34. Goodson N: Coronary artery disease and rheumatoid arthritis. Curr Opin Rheumatol 2002, 14:115-120.

35. Jacobsson LT, Knowler WC, Pillemer S, Hanson RL, Pettitt DJ, Nelson RG, del Puente A, McCance DR, Charles MA, Bennett PH: Rheumatoid arthritis and mortality. A longitudinal study in Pima Indians. Arthritis Rheum 1993, 36:1045-1053.

36. Del Rincon I, Williams K, Stern MP, Freeman GL, O'Leary DH, Escalante A: Association between carotid atherosclerosis and markers of inflammation in rheumatoid arthritis patients and healthy subjects. Arthritis Rheum 2003, 48:1833-1840

37. Jonsson SW, Backman C, Johnson O, Karp K, Lundstrom E, Sundqvist KG, Dahlqvist SR: Increased prevalence of atherosclerosis in patients with medium term rheumatoid arthritis. J Rheumato/ 2001, 28:2597-2602.

38. Nagata-Sakurai M, Inaba M, Goto H, Kumeda Y, Furumitsu Y, Inui K, Koyama H Emoto M, Ishimura E, Shoji T, Nishizawa Y: Inflammation and bone resorption as independent factors of accelerated arterial wall thickening in patients with rheumatoid arthritis. Arthritis Rheum 2003, 48:3061-3067.

39. Park YB, Ahn CW, Choi HK, Lee SH, In BH, Lee HC, Nam CM, Lee SK: Atherosclerosis in rheumatoid arthritis: morphologic evidence obtained by carotid ultrasound. Arthritis Rheum 2002, 46:1714-1719.

40. Turesson C, O'Fallon WM, Crowson CS, Gabriel SE, Matteson EL: Occurrence of extraarticular disease manifestations is associated with excess mortality in a community based cohort of patients with rheumatoid arthritis. J Rheumato/ 2002, 29:62-67.

41. Wallberg-Jonsson S, Cvetkovic JT, Sundqvist KG, Lefvert AK, RantapaaDahlqvist S: Activation of the immune system and inflammatory activity in relation to markers of atherothrombotic disease and atherosclerosis in rheumatoid arthritis. J Rheumatol 2002, 29:875-882.

42. Meune C, Touze E, Trinquart L, Allanore Y: Trends in cardiovascular mortality in patients with rheumatoid arthritis over 50 years: a systematic review and meta-analysis of cohort studies. Rheumatology (Oxford) 2009, 48:1309-1313.

43. Peters MJ, van Halm VP, Voskuyl AE, Smulders YM, Boers M, Lems WF Visser $M$ Stehouwer CD, Dekker JM, Nijpels G, Heine R, Dijkmans BA, Nurmohamed MT: Does rheumatoid arthritis equal diabetes mellitus as an independent risk factor for cardiovascular disease? A prospective study. Arthritis Rheum 2009, 61:1571-1579.

44. Krishnan E, Lingala VB, Singh G: Declines in mortality from acute myocardial infarction in successive incidence and birth cohorts of patients with rheumatoid arthritis. Circulation 2004, 110:1774-1779.

45. Gerli R, Bartoloni Bocci E, Sherer Y, Vaudo G, Moscatelli S, Shoenfeld Y: Association of anti-cyclic citrullinated peptide antibodies with subclinical atherosclerosis in patients with rheumatoid arthritis. Ann Rheum Dis 2008, 67:724-725.

46. Lopez-Longo FJ, Oliver-Minarro D, de la Torre I, Gonzalez-Diaz de Rabago E, Sanchez-Ramon S, Rodriguez-Mahou M, Paravisini A, Monteagudo I, Gonzalez CM, Garcia-Castro M, Casas MD, Carreno L: Association between anti-cyclic citrullinated peptide antibodies and ischemic heart disease in patients with rheumatoid arthritis. Arthritis Rheum 2009, 61:419-424.

47. Swanberg M, Lidman O, Padyukov L, Eriksson P, Akesson E, Jagodic M, Lobel A, Khademi M, Borjesson O, Lindgren CM, Lundman P, Brookes AJ, Kere J, Luthman H, Alfredsson L, Hillert J, Klareskog L, Hamsten A, Piehl F, Olsson T: MHC2TA is associated with differential MHC molecule expression and 
susceptibility to rheumatoid arthritis, multiple sclerosis and myocardial infarction. Nat Genet 2005, 37:486-494

48. Kumeda Y, Inaba M, Goto H, Nagata M, Henmi Y, Furumitsu Y, Ishimura E, Inui K, Yutani Y, Miki T, Shoji T, Nishizawa Y: Increased thickness of the arterial intima-media detected by ultrasonography in patients with rheumatoid arthritis. Arthritis Rheum 2002, 46:1489-1497.

49. Hansel S, Lassig G, Pistrosch F, Passauer J: Endothelial dysfunction in young patients with long-term rheumatoid arthritis and low disease activity. Atherosclerosis 2003, 170:177-180

50. Cvetkovic JT, Wallberg-Jonsson S, Ahmed E, Rantapaa-Dahlqvist S, Lefvert AK: Increased levels of autoantibodies against copper-oxidized low density lipoprotein, malondialdehyde-modified low density lipoprotein and cardiolipin in patients with rheumatoid arthritis. Rheumatology (Oxford) 2002, 41:988-995

51. Winyard PG, Tatzber F, Esterbauer H, Kus ML, Blake DR, Morris CJ: Presence of foam cells containing oxidised low density lipoprotein in the synovial membrane from patients with rheumatoid arthritis. Ann Rheum Dis 1993, 52:677-680.

52. Rho YH, Chung CP, Oeser A, Solus JF, Gebretsadik T, Shintani A, Raggi P, Milne $\mathrm{GL}$, Stein CM: Interaction between oxidative stress and high-density lipoprotein cholesterol is associated with severity of coronary artery calcification in rheumatoid arthritis. Arthritis Care Res (Hoboken) 2010, 62:1473-1480

53. van Eden W, van der Zee R, Prakken B: Heat-shock proteins induce T-cell regulation of chronic inflammation. Nat Rev Immuno/ 2005, 5:318-330

54. Hurt-Camejo E, Paredes S, Masana L, Camejo G, Sartipy P, Rosengren B, Pedreno J, Vallve JC, Benito P, Wiklund O: Elevated levels of small, lowdensity lipoprotein with high affinity for arterial matrix components in patients with rheumatoid arthritis: possible contribution of phospholipase A2 to this atherogenic profile. Arthritis Rheum 2001, 44:2761-2767.

55. Hafstrom I, Rohani M, Deneberg S, Wornert M, Jogestrand T, Frostegard J: Effects of low-dose prednisolone on endothelial function, atherosclerosis, and traditional risk factors for atherosclerosis in patients with rheumatoid arthritis - a randomized study. J Rheumato/ 2007, 34:1810-1816.

56. Dessein PH, Joffe Bl, Stanwix AE: Effects of disease modifying agents and dietary intervention on insulin resistance and dyslipidemia in inflammatory arthritis: a pilot study. Arthritis Res 2002, 4:R12.

57. Branen L, Hovgaard L, Nitulescu M, Bengtsson E, Nilsson J, Jovinge S: Inhibition of tumor necrosis factor-alpha reduces atherosclerosis in apolipoprotein E knockout mice. Arterioscler Thromb Vasc Biol 2004, 24:2137-2142

58. Hyrich KL, Silman AJ, Watson KD, Symmons DP: Anti-tumour necrosis factor alpha therapy in rheumatoid arthritis: an update on safety. Ann Rheum Dis 2004, 63:1538-1543

59. Jacobsson LT, Turesson C, Gulfe A, Kapetanovic MC, Petersson IF, Saxne T, Geborek P: Treatment with tumor necrosis factor blockers is associated with a lower incidence of first cardiovascular events in patients with rheumatoid arthritis. J Rheumato/ 2005, 32:1213-1218.
60. Maki-Petaja KM, Booth AD, Hall FC, Wallace SM, Brown J, McEniery CM, Wilkinson IB: Ezetimibe and simvastatin reduce inflammation, disease activity, and aortic stiffness and improve endothelial function in rheumatoid arthritis. J Am Coll Cardiol 2007, 50:852-858.

61. Eder L, Zisman D, Barzilai M, Laor A, Rahat M, Rozenbaum M, Bitterman H, Feld J, Rimar D, Rosner I: Subclinical atherosclerosis in psoriatic arthritis: a case-control study. J Rheumato/ 2008, 35:877-882

62. Tam LS, Shang Q, Li EK, Tomlinson B, Chu TT, Li M, Leung YY, Kwok LW, Wong KC, Li TK, Yu T, Zhu TY, Kun EW, Yip GW, Yu CM: Subclinical carotid atherosclerosis in patients with psoriatic arthritis. Arthritis Rheum 2008 59:1322-1331.

63. Tobin AM, Veale DJ, Fitzgerald O, Rogers S, Collins P, O'Shea D, Kirby B: Cardiovascular disease and risk factors in patients with psoriasis and psoriatic arthritis. J Rheumatol 2010, 37:1386-1394.

64. Lehtinen K: Mortality and causes of death in 398 patients admitted to hospital with ankylosing spondylitis. Ann Rheum Dis 1993, 52:174-176.

65. Han C, Robinson DW, Jr, Hackett MV, Paramore LC, Fraeman KH, Bala MV: Cardiovascular disease and risk factors in patients with rheumatoid arthritis, psoriatic arthritis, and ankylosing spondylitis. J Rheumato/ 2006, 33:2167-2172.

66. Zochling J, Braun J: Mortality in rheumatoid arthritis and ankylosing spondylitis. Clin Exp Rheumatol 2009, 27(4 Suppl 55):S127-S130.

67. Noto N, Okada T, Yamasuge M, Taniguchi K, Karasawa K, Ayusawa M, Sumitomo N, Harada K: Noninvasive assessment of the early progression of atherosclerosis in adolescents with Kawasaki disease and coronary artery lesions. Pediatrics 2001, 107:1095-1099.

68. Cantu C, Pineda C, Barinagarrementeria F, Salgado P, Gurza A, Paola de P, Espinosa R, Martinez-Lavin M: Noninvasive cerebrovascular assessment of Takayasu arteritis. Stroke 2000, 31:2197-2202.

69. Kawai S, Fukuda Y, Okada R: Atherosclerosis of the coronary arteries in collagen disease and allied disorders, with special reference to vasculitis as a preceding lesion of coronary atherosclerosis. Jpn Circ J 1982, 46:1208-1221.

70. Alan S, Ulgen MS, Akdeniz S, Alan B, Toprak N: Intima-media thickness and arterial distensibility in Behcet's disease. Angiology 2004, 55:413-419.

71. de Leeuw K, Sanders JS, Stegeman C, Smit A, Kallenberg CG, Bijl M: Accelerated atherosclerosis in patients with Wegener's granulomatosis. Ann Rheum Dis 2005, 64:753-759.

72. Krishnan E: Inflammation, oxidative stress and lipids: the risk triad for atherosclerosis in gout. Rheumatology (Oxford) 2010, 49:1229-1238.

doi:10.1186/ar3326

Cite this article as: Frostegård J: Cardiovascular co-morbidity in patients with rheumatic diseases. Arthritis Research \& Therapy 2011, 13:225. 